\title{
Héctor Viel Temperley: \\ DE LA INVISIBILIDAD A LA CATEGORÍA DE "POETA DE CULTO" http://dx.doi.org/10.1590/1984-0292/1329
}

\author{
Mg. Cristina Piña
}

Universidad Nacional de Mar del Plata, Mar del Plata, Argentina

\begin{abstract}
RESUMEN
En el presente artículo, se comprueba cómo la adopción de ciertas categorías teórico-críticas impide la visibilidad de ciertos escritores que no se adecuan a ellas. Es el caso del poeta argentino Héctor Viel Temperley, invisible cuando se enfoca la literatura desde las categorías sociológico-estructurales de Pierre Bourdieu, que entienden el campo intelectual como un mercado de puestos fijos donde grupos de escritores ocupan espacios prefijados. Enfocado desde nociones deleuzianas como nomadismo, rizoma, desterritorialización y minoración y de las operaciones de visibilidad de Rancière, pasó a ser visible y a ocupar un lugar de privilegio para la crítica argentina de poesía.
\end{abstract}

Palabras clave: estructura del campo intelectual; nomadismo; rizoma; minoración.

\section{Héctor Viel Temperley: FROM INVISIBILITY TO THE CATEGORY OF "CULT POET"}

\begin{abstract}
This article shows that working with certain theoretical-critical categories makes invisible those writers who do not fit within them. We will concentrate on the Argentine poet Héctor Viel Temperley, who becomes invisible when you consider literature from sociological categories such as Pierre Bourdieu's "structure of the intellectual field", that understands it as a market with fix positions where groups of writers occupy pre-established places. Considering him from Deleuzian notions such as nomadism, rhizome, deterritorialization, and minoration, as well as from Rancière's idea of visibility operations, becomes not only visible but occupies a specially privileged place for Argentine poetry critics.
\end{abstract}

Keywords: structure of the intellectual field; nomadism; rhizome; minoration.

^ Dirección de envio: Universidad Nacional de Mar del Plata - Diagonal J. B. Alberdi 2695-

(7600) - Mar del Plata - Argentina.E-mail: cpinaorama@gmail.com 
Como nos lo demuestra ampliamente la historia literaria, las diversas épocas no han estado, en muchos casos, a la altura de los autores que en ellas escribieron, dejándolos perdidos en el laberinto de la invisibilidad y la no legitimación.

Desde Stendhal, quien era consciente de que sólo lo comprendería la generación siguiente, hasta Mallarmé, considerado ilegible por gran parte de sus contemporáneos o, ya en el campo de la filosofía, Nietzsche, sólo valorado como filósofo a partir de los años treinta del siglo XX, los ejemplos sobran, con la consecuente transformación del artista en una especie de Minotauro encerrado en el laberinto de su obra ilegible durante gran parte o la totalidad de su vida productiva.

Si reparamos en nuestra literatura, más allá de la tardía recepción de Borges -y eso gracias a que los postestructuralistas franceses se erigieron en Teseos de nuestro Asterión- son buenos ejemplos Héctor Viel Temperley y Amelia Biagioni, quienes escribieron toda su obra poética con muy escaso reconocimiento crítico.

Sin entrar en generalizaciones o indagaciones acerca de la multiplicidad de motivos que pueden, en cada caso, haber determinado la dificultad de su lectura por parte de los contemporáneos, me interesa especialmente el caso de Héctor Viel Temperley (2009), ya que uno de los factores importantes para la no comprensión de su poesía, fue tanto la carencia de instrumentos teóricos adecuados para abordarla como una suma de prejuicios ideológicos.

Porque, dentro de un ámbito universitario y crítico que, más allá de las aperturas a ciertos autores del postestructuralismo francés -Foucault en primer lugar, luego Derrida y Deleuze y ahora Rancière-, en el plano del enfoque de la evolución literaria se avanzó poco más allá del formalismo ruso para quedar capturado - a pesar de la incorporación parcial de la Escuela de Constanza- en el rígido esquema de la "estructura del campo intelectual" postulado por Pierre Bourdieu (1973, p. 21) -con su delimitación de lugares fijos para comprender el estado de un determinado momento literario-, pocas posibilidades de comprensión tenía un poeta esencialmente autónomo y erótico-religioso como Viel. Porque no pertenecía a ningún grupo ni estética fijos y fue cambiando su estilo y su ubicación en el panorama de la poesía argentina a partir tanto de una progresiva experimentación con la palabra como de algo repudiable para los herederos de la vanguardia: una religiosidad totalmente heterodoxa que al final llega a la mística, también heterodoxa, pero mística al fin.

Y si Jacobo Fijman (2007) fue inasimilable salvo para algunos compañeros de su generación ${ }^{1}$ y tuvieron que pasar años para que se le consagraran estudios y se reuniera su obra, más grave aún es el caso de Viel, quien además no llevaba la prestigiosa marca de la locura. Porque, no nos engañemos, hay algo profundamente atractivo en el poeta loco o que bordea la demencia, a partir de una visión romántica del arte que hasta a los más reacios de nuestros críticos a veces los seduce. Si a eso le sumamos su condición de inmigrante, judío converso, pobre y marginal resulta bastante más asimilable para partidarios de perspectivas estructuralistas y de base marxista, como es el caso de Pierre Bourdieu. 
En cambio, cuando pasamos a Héctor Viel Temperley (2009), nos encontramos con una figura totalmente diferente, tanto por sus orígenes como por su trayectoria literaria, por la peculiaridad -o extraterritorialidad- de su poesía mística y por los avatares de su recepción según veremos más adelante.

Hasta ahora, con toda deliberación he evitado utilizar los conceptos de Deleuze (1993) Deleuze y Guattari (1980) y otros teóricos como Rancière (2011a; 2011b) que resultan capitales para dar cuenta de una producción y una trayectoria de estas características -nomadismo, rizoma, territorialización/desterritorialización, operaciones de visibilización, etc.- a fin de transmitir de alguna manera la dificultad de leerlo con el enfoque histórico-teórico en boga.

Es decir, que mientras consideremos al panorama de nuestra literatura $-\mathrm{O}$ de cualquier otra- como un mercado de puestos fijos - para tomar las palabras de Bourdieu (1973, p. 21)- sólo podremos distinguir en él a aquellos escritores que tienen vocación sedentaria y gregaria -en el sentido de formar grupos con propuestas estéticas comunes y más o menos cristalizadas- y que están instalados en una subjetividad más o menos estable en el sentido de no hallarse problematizada en su escritura.

En cambio, cuando visualizamos al supuesto "panorama" como una superficie que va ampliándose y transformándose continuamente, según una dinámica nómada y rizomática y a la estética relacionada con un régimen de repartición de lo sensible (RANCIÈRE, 2010), el laberinto donde está cautiva la obra ilegible deja de ser un espacio cerrado y carcelario, para convertirse en un trayecto, y el Minotauro en él confinado despliega su singularidad frente al lector.

A este enfoque, asimismo, debemos agregar la operación de visibilidad que realiza Fogwill en plena década del ochenta, dentro del contexto de su construcción personal de una "figura de autor" (PREMAT, 2009) que rompe por un lado con Borges y por otro con la concepción de la literatura como compromiso que prevaleció durante los sesenta y setenta. Porque, tanto como Fogwill (2007) edita a Néstor Perlongher, Leónidas y Osvaldo Lamborghini y promueve a nuevos narradores -desde César Aira y Alberto Laiseca, hasta Marcelo Cohen, Sergio Bizzio y Hebe Uhart (FOGWILL, 2010) - difundirá la poesía de su amigo Héctor Viel Temperley (FOGWILL, 2007). ${ }^{2}$

\section{II}

\section{Mística, erotismo y transgresión formal}

Por empezar, a diferencia de Fijman (2007), Viel Temperley (2009) pertenecía a una familia de clase media alta que tenía campos, gracias a lo que pudo entrar en contacto con el paisaje rural argentino -a tal punto importante en sus primeros libros-, así como con el mar, en veraneos donde empieza a desarrollar su pasión de nadador y su amor por el mar, que adquirirá un valor simbólico fundamental en su poesía. 
También, frente al misógino y mentalmente desequilibrado hijo de inmigrantes, Viel formó una familia de siete hijos - con quienes mantuvo una relación singularmente entrañable y cariñosa hasta el fin de su vida- por más que rompió el matrimonio a causa de su vocación de escritor, como lo señala Juan Forn (2010, p. 12), amigo de su hija Verónica: “[...] ella quería que yo conociera a un poeta de verdad, un tipo que había dejado a su mujer y a sus hijos, además de su cómodo trabajo y su clase social, para dedicarse a escribir poesía."

Por más que la explicación es sin duda acertada, también habría que tener en cuenta el tipo de poesía de Viel, en la que la religiosidad se va acendrando hasta que se opera ese "salto fuera del mundo" que implica la unión mística con Dios hecha palabra en su último libro, Hospital Británico (1986). Y ese acendramiento es sinónimo de apartarse del mundo e imponerse una disciplina —que, sin embargo, no remite a la ascética, como veremos.

Volviendo a la comparación con Fijman (2007), cuando pasamos a considerar la trayectoria de ambos, surge una diferencia de signo opuesto, ya que frente a la participación de Fijman en la vanguardia del 20, Viel Temperley (2009) fue un autor casi totalmente secreto y excluido de todas las manifestaciones vinculadas con la poesía y la literatura de las décadas del 50 al 70, exclusión que se mantiene hasta la aparición de sus dos últimos libros en la del 80 , durante la cual murió. Me refiero a Crawl (1982) y Hospital Británico, libros que sin duda despertaron interés, sino estupefacción, a raíz de la profunda transgresión formal que aportaban y de la extraterritorialidad de su planteo religioso y místico.

Sin embargo, entre 1956 -fecha de Poemas con caballos- y 1978, en que aparece Legión Extranjera, el autor había publicado siete libros, solamente uno en una editorial importante -El nadador de 1967 en Emecé- y sus contactos con escritores se limitaban al gran poeta surrealista argentino Enrique Molina, casi una generación menor que Viel, al poeta de la generación siguiente a la de Viel, Fernando Sánchez Sorondo - amistad vinculada más que con lo estrictamente literario con la relación de aquél con una de sus hijas, y que escribe la contratapa de su libro Febrero 72 Febrero 73 (1973)- y Fogwill, de su misma generación, a quien lo vinculaba, más allá de una similar ascendencia inglesa, el hecho de que ambos trabajaran en el ámbito de la publicidad. Fogwill, además, fue fundamental para el rescate de su obra a partir de 1991, ya que, gracias a su insistencia en el valor de la poesía de Viel, la revista Diario de Poesía -de singular importancia tras la recuperación de la democracia en la Argentina- le dedicó el dossier de "Poesía Argentina" en el número 19 de ese año, lo cual marcó el comienzo de la verdadera recepción de su obra.

Una vez iniciado el camino de recuperación y nuevamente en oposición a lo ocurrido con la obra de Fijman (2007), ${ }^{3}$ Viel se convirtió primero en escritor de culto -denominación que personalmente rechazo porque me parece que encubre la mala conciencia de quienes así lo califican a causa del desinterés editorial en la obra- para luego circular por la Universidad, generar una serie de estudios tanto breves como extensos, la publicación de dos libros enteramente dedicados a su poesía, la redacción de una tesis doctoral y, lo fundamental, la reedición, primero 
de sus dos últimos libros en un solo volumen en 2001 y luego de su Obra completa (VIEL TEMPERLEY, 2009), aparecidos, no por casualidad, en la misma editorial que editó la de Fijman: Ediciones del Dock.

Por cierto que no fue la ceguera crítica lo único que le impidió figurar en nuestra poesía, sino que como él mismo lo dice no le interesaba integrarse en grupos:

- Creo que eso es culpa mía. No hice ningún movimiento para acercarme. No estuve en ningún grupo. Siempre rehuí las presentaciones. Y hasta Carta de Marear, que apareció en 1978, había publicado cinco libros... (BIZZIO, 1987, p.75, las cursivas son del autor)

Ahora bien, más allá de tal actitud, considero que hay diversos aspectos en su obra que la vuelven especialmente difícil de asimilar para el contexto de la época, tanto por su contenido religioso y místico como por sus aspectos estéticos y su tratamiento del cuerpo y la sexualidad, la suma de los cuales lo convierten en un "nómade extraterritorial", según lo he calificado siguiendo a la vez la denominación de Deleuze (1979) y de George Steiner (1971). Un extraterritorial de la mística, un extraterritorial de la poesía, un extraterritorial del mercado que, va formando rizoma con campos tan alejados como la mística castellana del siglo XVI -San Juan de la Cruz y Santa Teresa de Ávila-, el surrealismo -tanto francés como argentino, sobre todo en la figura de su amigo Enrique Molina-, la tradición sobre todo surrealista de la poesía erótica, la poesía campestre argentina -ante todo la tradición nacionalista de la Generación del 40 argentina- y, ya en el campo extrapoético y textual, con la disciplina del deporte - sobre todo la natación.

En lo que se relaciona con la mística, parto de una reflexión de Cristóbal Cuevas (1980) sobre lo que determina los singulares logros estéticos de la mística de Santa Teresa y San Juan de la Cruz dentro del ámbito hispánico. Para el estudioso: "[...] su ideario se ajustaba mejor que ningún otro al espíritu de los tiempos" (CUEVAS, 1980, p. 492). Si consideramos desde esta perspectiva la poesía de Viel Temperley, nos tropezamos con una ambigüedad que constituye el primero de los obstáculos para su recepción por parte del público y la crítica contemporáneos.

Tanto como en la cultura del siglo XX se ha revalorizado el cuerpo y se ha legalizado su representación, al igual que la del erotismo en general, en la literatura y el arte, la religión católica ha mantenido su tradicional actitud de desvalorización del cuerpo. Si a ello sumamos que en el Cristianismo el camino hacia la unión mística se apoya precisamente en una ascética -que entraña el rechazo del cuerpo, el anonadamiento de la subjetividad y la purgación de lo sensorial para permitir el encuentro pasivo con Dios- la exaltación del cuerpo presente en la poesía de Viel, su transformación de dicha ascética en "entrenamiento atlético" o "deporte de Dios" (MILONE, 2003) -encarnados en la natación o el ejercicio rítmico de hachar- implica un cambio radical que parece llevarnos al terreno opuesto. 
Y si digo "parece" es porque tal ruptura para nada entraña que Viel adopte esa otra forma de mística contemporánea no religiosa representada por "la experiencia interior" de Georges Bataille (1943), donde lo que se experimenta no es la presencia sino la ausencia de Dios, según lo señala acertadamente Gabriela Milone (2003, p. 15-21).

Y ese rasgo que, por un lado, lo hace más accesible para quienes no se interesan por la mística pero se sienten atraídos por la sensualidad de su poesía, implica un factor de incomodidad para los ortodoxos, que a menudo quedan desconcertados ante ella. Es decir, que no acomoda del todo en ningún lado

En rigor, la mística de Viel es una mística "encarnada” en el sentido de que, yendo más allá de las tradicionales metáforas amorosas utilizadas para la representación de la unión del alma con Dios que inaugura el Cantar de los cantares y retoma San Juan de la Cruz, en su poesía hay una fuerte presencia de la sensualidad y la sexualidad, de esa "carne" desestimada como impura por la ortodoxia cristiana.

Este rasgo lo vemos ya en el principio mismo de su poesía, donde hay una religiosidad que pasa necesariamente por el cuerpo. Pienso en Poemas con caballos, donde en "El arma" es innegable esa exaltación, como advertimos aquí: ${ }^{4}$

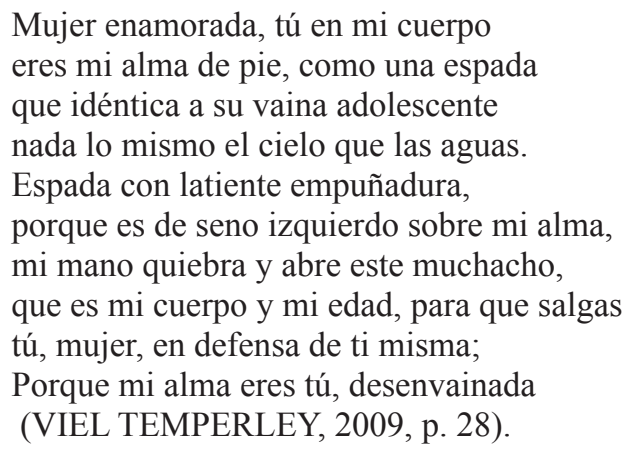

Una exaltación similar en Humanae vitae mia (1969) lo lleva a reafirmar la carne desde el mismo Adán, como se percibe en el comienzo de "Qué horror el paraíso":

Qué horror el paraíso

si Adán no hubiera amado

la carne de su carne

(VIEL TEMPERLEY, 2009, p. 101).

Gesto que en el libro Plaza batallón 40 (1971) pasa a ser sacralización de la sexualidad, según se advierte en el poema "Cataratas" (VIEL TEMPERLEY, 2009, p. 189-190), uno de los que anticipan, en su planteo, el excepcional poema "Equitación” de Legión Extranjera (1978). 
Este resulta singularmente complejo por sus peculiaridades formales -que por cuestiones de espacio no tomaré en consideración- pero también por la potente carga erótica del poema, en tanto que la sexualidad está aludida de manera directa y articulada con elementos religiosos:

De espaldas sobre el mundo
con esta bayoneta cavé en ellas
En esa misma posición yo quiero
que escuches este informe sin dormirte:
Las obligaba a mantenerse erguidas
y a hablar así mirándome a los ojos
a pesar del pudor sin derramarse
hacia mi cuerpo inmóvil
como amazonas en la silla cómodas
pero estribando corto
Y al paso al trote o nuevamente al paso
cada vez que el silencio me enfrentaba
o entre nubes de arena divisaba volando
una nueva cometa rasante peligrosa
de una valla a otra valla las oía
Y las primeras veces que ocultando sus pechos
y sus rostros caían sus cabellos
eran mis manos las que los apartaban
porque al comienzo ellas no se atreven
a tocárselos siquiera
y para hablar sin luz se sirven de ellos
como de las rejillas de los confesionarios

(VIEL TEMPERLEY, 2009, p. 290-291).

Para culminar este breve recuento y antes de referirme brevemente a la presencia del cuerpo en el único poema radicalmente místico de Viel, Hospital Británico, quiero citar el verso con el que termina la TERCERA PARTE de Legión Extranjera, Aquí AMANECE GRIS Y EL VIENTO TRAE VIOLETAS, porque sintetiza esa articulación entre erotismo y religiosidad: "Hombre que fornica mientras espera el Reino" (VIEL TEMPERLEY, 2009, p. 311)

Como en un artículo llamado precisamente "Viel Temperley, el místico extraterritorial" (AA.VV., 2011, p. 121-135) he analizado en detalle diversos aspectos formales y de contenido de Hospital Británico, me excuso de hacerlo aquí. Sin embargo, al menos me detendré en un ejemplo donde la presencia del cuerpo resulta singularmente estremecedora, y no sólo el cuerpo del sujeto lírico sino el del propio Cristo. Así en la "esquirla"5 "Tengo la cabeza vendada" (textos proféticos) dice:

Santa Reina de los misterios del rosario del hacha y de las brazadas lejos del espigón: Ruega por mí que estoy en una zona donde nunca había anclado con maniobras de Cristo en mi cabeza. 
Señor: Desde este instante mi cabeza quiere ser, por los siglos de los siglos, la herida de Tu Mano bendiciéndome en fuego .

El sol como la blanca velocidad de Dios en mi cabeza, que la aspira y la desgarra hacia la nuca (VIEL TEMPERLEY, 2009, p. 381-382).

Pero además, los aspectos formales de su producción lo apartaban per se de los "puestos" aludidos por Bourdieu (1973, p. 21). Su poesía se escribe a contrapelo de casi todo lo valorado por los poetas coetáneos y posteriores y de las poéticas defendidas por los grupos y cenáculos del 50 al 70. Pensemos, si no, que cuando en plenos años cincuenta -liderados por la revista Poesía Buenos Aires- está mal vista la poesía que recurre a metros y formas tradicionales, se muestra demasiado "argentina" en la valoración del campo y el entorno pampeano o desarrolla una dimensión religiosa, Viel escribe romances y poemas donde la admiración por el campo y sus rituales se articula con una fuerte presencia de elementos religiosos, así como con una sensualidad poco común en la época, si exceptuamos precisamente a su amigo Enrique Molina.

Y ya después, el elemento religioso-místico se imbrica, además, con imágenes de un surrealismo deslumbrante y con una ruptura de la dimensión formal que alcanzará sus dos momentos más extremos en los libros finales. Hasta este punto, entonces, las transgresiones -ante todo su articulación entre transgresión formal y religiosidad- y el nomadismo del autor parecen no ser asimiladas por la crítica sea por remitir a una poética anticuada, sea por operar una renovación demasiado drástica.

Y cuando llegamos a Crawl y Hospital Británico, las formas saltan por el aire y las vemos estallar sea por medio de la repetición y lo gráfico para que el poema haga lo que dice-Crawl y su intento de reproducir gráficamente las brazadas de ese estilo de natación- sea por intentar poner en lenguaje y en el espacio de la página el estallido de la realidad humana para que aparezca, por un lado, la del otro Reino, pero, por el otro, para identificarlo con la trepanación del cráneo que sufre el autor a raíz del tumor que lo aqueja. Esto lo logra deshaciendo el bellísimo poema "Hospital Británico Mes de Marzo de 1986" que abre el libro, en la Versión con esquirlas y "Christus Pantokrator" (VIEL TEMPERLEY, 2009, p. 373-387) que se sucede a continuación.

En este sentido, la minoración de la lengua (DELEUZE; GUATTARI, 1975; DELEUZE, 1979, 1993) que practica Viel llega a un extremo de agramaticalidad casi único en la poesía argentina de la época, a la que se suma su peculiar "minoración" del lenguaje místico, articulándolo con el corporal y sexual y con el del deporte, hasta llevarnos a un sintagma tan transgresor como entender la natación como "deporte de Dios".

Por fin, y antes de terminar esta revisión parcial de la obra de Viel, creo importante señalar que la presencia del erotismo y la sexualidad en su poesía no sólo resultan poco comunes por convivir con la religiosidad y la mística, sino por 
el pudor -o silencio- en relación con ellos propio de la poesía argentina. Porque, si excluimos precisamente a Enrique Molina, hasta la década del 80, con Osvaldo Lamborghini ${ }^{6}$ y Néstor Perlongher, nuestra poesía elude el erotismo.

Para cerrar estas reflexiones, quiero compartir el único y bellísimo poema que quedó inédito tras la muerte de Viel en 1987 y que, generosamente, sus hijos imprimieron y repartieron entre los que estuvimos en el homenaje que se le tributó al cumplirse veinticinco años de su muerte, el 26 de junio de 2012

\section{Magenta}

Magenta es la barba de Cristo. Como rompiente de mar moja mi rostro: en mi nariz dibuja su nariz y en sus ojos cerrados pone mis ojos. En mi cara suda, su sangre corre por ella desde el pelo.

Así empapado estoy con Él, esperando su Resurrección.

Me duele su nariz, su cabeza, su barba, sus labios.

Soy más que un trapo suave, lleno de sueño, blanco de nacimiento; y soy más que una máscara sobre nariz partida, barba arrancada.

Soy un hombre sobre otro, una boca sobre otra, un beso para Dios pero en la tierra, donde nadie ve al hombre.

Soy antes y después, en Él, magenta; de sus labios es imposible despegar los míos. (VIEL TEMPERLEY, 2012, Inédito) 


\section{Notas}

${ }^{1}$ Me refiero a la Generación martinfierrista que a partir de los años 20 y parte de los 30 desarrolla una poesía vanguardista y reñida con las corrientes predominantes en la época: el tardo-modernismo y la poesía social del grupo de Boedo.

${ }^{2}$ A la insistencia de Fogwil se le debe la publicación de poemas de Viel Temperley (2009) en Diario de poesía acompañados por una nota propia.

${ }^{3}$ Jacobo Fijman publica en vida sólo tres libros: Molino Rojo (1926); Hecho de Estampas (1930) y Estrella de la mañana (1931), si bien sigue escribiendo tras su internación definitiva en el Hospital Borda con el diagnóstico de síndrome confusional o psicosis distímica confusional (ARANCET RUDA, 2001, p. 9). Estos poemas se reúnen parcialmente en Obra poética (1983) y en su totalidad en la Poesía completa (2005).

${ }^{4}$ Todas las citas de poemas de Viel Temperley (2009) pertenecen a su Obra completa

${ }^{5}$ El propio poeta denomina así a la segunda versión del poema que constituye el libro -"Hospital Británico Mes de marzo de 1986" (Versión con esquirlas y Christus Pantokrator)- y que como señalaré a continuación hace estallar a la primera en múltiples fragmentos.

${ }^{6} \mathrm{Si}$ bien Lamborghini escribe poesía durante la década del 70, sus poemas sólo se publican en la revista Literal y aparecen en libro en 1980.

\section{REFERENCIAS}

AA.VV. Viel Temperley. Buenos Aires: Dock, 2011. Col. Época.

ARANCET RUDA, M. A. Jacobo Fijman: una poética de las huellas. Buenos Aires: Corregidor, 2002.

BATAILLE, G. L’Expérience intérieure. París: Gallimard, 1943.

BIZZIO, S. Viel Temperley: Estado de Comunión". Vuelta Sudamericana, Buenos Aires, n. 12, jul. 1987. Disponible en: <http://www.panfletonegro.com/ melancopolis/hectorvieltemperley.shtml>. Consultada en: 10 enero 2010.

BOURDIEU, P. Campo del poder y campo intelectual. Buenos Aires: Folios, 1973.

CUEVAS, C. Santa Teresa, San Juan de la Cruz y la literatura espiritual. En: RICO, F. (Coord.). Historia y crítica de la literatura española - II. Francisco López Estrada. Siglos de Oro: Renacimiento. Barcelona: Crítica, p. 490-500, 1980.

DELEUZE, G. Un manifiesto menos. In: BENE, C.; DELEUZE, G. Superposiciones. Buenos Aires: Artes del Sur, 1979. p. 75-102.

DELEUZE, G. Crítica y clínica. Barcelona: Anagrama, 1993.

DELEUZE, G.; GUATTARI, F. Kafka: por una literatura menor. México: Era, 1975. 
DELEUZE, G.; GUATTARI, F. Mil mesetas: capitalismo y esquizofrenia. Barcelona: Pre-textos, 1980.

DIARIO DE POESÍA. “Héctor Viel Temperley”, n. 19, Invierno, 1991.

FIJMAN, J. Poesía completa. Buenos Aires: Dock, 2007. Colección Pez Náufrago.

FOGWILL, R. Rodolfo Fogwill habla de la poesía que aún admira. En: Clarin, viernes 14 de diciembre, 2007 Disponible en: <http://edant.clarin.com/ diario/2007/12/14/sociedad/s-05101.htm>. Consultado el: 21 jun. 2014.

FOGWILL, R. Los libros de la guerra. 2. ed. Buenos Aires: Mansalva, 2010.

FORN, J. "El sacado del mundo" en Página 12 - Verano 12. Jueves 18 de febrero, 2010. Disponible en: <http://www.pagina12.com.ar/diario/ verano12/23-140533-2010-02-18.html>. Consultada en: 22 mayo 2014.

MILONE, M. G. Héctor Viel Temperley: el cuerpo en la experiencia de Dios. Córdoba: Ferreyra, 2003. Col. Lecturas Mínimas.

PREMAT, J. Héroes sin atributos: figuras de autor en la literatura argentina. Buenos Aires: Fondo de Cultura Económica, 2009.

RANCIÈRE, J. Le partage du sensible: esthétique et politique. París: La Fabrique, 2010.

RANCIÈRE, J. El malestar en la estética. Buenos Aires: Capital Intelectual, 2011a.

RANCIÈRE, J. Política de la literatura. Buenos Aires: Libros del Zorzal, 2011 b.

STEINER, G. Extraterritorial: ensayos sobre la literatura y la revolución del lenguaje. Buenos Aires: Adriana Hidalgo, 1971.

VIEL TEMPERLEY, H. Obra completa. Buenos Aires: Dock, 2009. Colección Pez Náufrago.

Recibido: 02 de julio 2014 Aceptado: 03 de septiembre 2014 